LBL-38573

UC- 1240

\title{
ADVANCES IN THE TOUGH2 FAMILY OF GENERAL-PURPOSE RESERVOIR SIMULATORS
}

Karsten Pruess, Stefan Finsterle, George Moridis, Curt Oldenburg, Emilio Antunez, and Yu-Shu Wu

Earth Sciences Division

Emest Orlando Lawrence Berkeley National Laboratory

University of California

Berkeley, CA 94720

Paper presented at the

U.S. Department of Energy

Geothermal Program Review XIV

April 8-10, 1996

Berkeley, California

April 1996

This work was supported by the Assistant Secretary for Energy Efficiency and Renewable Energy, Geothermal Division, U.S. Department of Energy under Contract No. DE-AC03-76SF00098. 


\section{DISCLAIMER}

This report was prepared as an account of work sponsored by an agency of the United States Government. Neither the United States Government nor any agency Thereof, nor any of their employees, makes any warranty, express or implied, or assumes any legal liability or responsibility for the accuracy, completeness, or usefulness of any information, apparatus, product, or process disclosed, or represents that its use would not infringe privately owned rights. Reference herein to any specific commercial product, process, or service by trade name, trademark, manufacturer, or otherwise does not necessarily constitute or imply its endorsement, recommendation, or favoring by the United States Government or any agency thereof. The views and opinions of authors expressed herein do not necessarily state or reflect those of the United States Government or any agency thereof. 


\section{DISCLAIMER}

Portions of this document may be illegible in electronic image products. Images are produced from the best available original document. 


\title{
ADVANCES IN THE TOUGH2 FAMILY OF GENERAL-PURPOSE RESERVOIR SIMULATORS
}

\author{
Karsten Pruess, Stefan Finsterle, George Moridis, Curt Oldenburg, Emilio Antunez, and Yu-Shu Wu \\ Earth Sciences Division, Lawrence Berkeley National Laboratory \\ (510) 486-6732; K_Pruess@lbl.gov
}

\begin{abstract}
TOUGH2 is a general-purpose fluid and heat flow simulator, with applications in geothermal reservoir engineering, nuclear waste disposal, and environmental contamination problems. This report summarizes recent developments which enhance the useability of the code, and provide a more accurate and comprehensive description of reservoir processes.
\end{abstract}

\section{INTRODUCTION}

Geothermal reservoir simulation is a mature technology which is now routinely used in the assessment, development, and management of geothermal resources (Bodvarsson et al., 1986). Advances continue to improve the description of reservoir processes, enhance the numerical efficiency for solving large problems on small computers, and generally increase the utility of reservoir simulators as practical engineering tools.

Research into mathematical modeling and numerical simulation of geothermal reservoir processes has been conducted at the Berkeley lab for almost twenty years. Since the late $1980 \mathrm{~s}$, mathematical modeling of fluid and heat flow has increasingly emphasized problems in nuclear waste disposal and environmental contamination. Geothermal reservoir simulation now benefits from advances made in these areas.

The general objective of our work is to improve the power and utility of geothermal reservoir simulation as a robust and practical engineering tool. By making state-of-the-art simulation capabilities widely available to the geothermal community, we hope to reduce uncertainties in geothermal reservoir delineation and evaluation. Specific goals include (i) more comprehensive and accurate description of reservoir processes, (ii) improved numerical algorithms, (iii) enhanced portability and ease of use of the simulator, (iv) development of novel applications of interest to the geothermal community, and (v) technology transfer and technical support for the TOUGH/MULKOM user community.

The TOUGH2 general-purpose simulator was released to the public in 1991 through the Department of Energy's software distribution centert (Pruess, 1991). Subsequently a large number of enhancements have been developed. Some of these have also been released, while others are undergoing betatesting or are limited to in-house use at the present time (see Table 1). In this paper we focus on recent developments that are of interest to the geothermal community.

\section{NEW RELEASES}

Most of the computational work in a reservoir simulation arises in the solution of large sets of coupled linear equations. The 1991 release of TOUGH2 provided only one method for this task, namely, direct solution by sparse matrix methods. While this is a very stable and robust approach, storage requirements and numerical work increase rapidly with problem size and matrix bandwidth. The practical limit for 2-D problems is of the order of 2,000 grid blocks, while 3-D problems are limited to a few hundred grid blocks. To covercome these limitations, a set of three preconditioned conjugate gradient solvers was added to TOUGH2 (T2CG1; see Table 1). These solvers use iterative methods, whose computational work and memory requirements increase only slightly faster than linearly with problem size, making possible the solution of large 2-D and 3-D problems with of the order of 10,000 grid blocks. A technical report (Moridis and Pruess,

\footnotetext{
† Energy Science and Technology Software Center (ESTSC), P.O. Box 62, Oak Ridge, TN 37831, phone (423) 576-2606, fax (423) 576-2865 email: estsc@adonis.osti.gov
} 
Table 1. Summary of TOUGH2 enhancements. Status codes are: (PR) public release, ( $\beta$ ) beta-testing underway, (i) in-house use only. Additional developments not shown in this table include coupling with a wellbore simulator (Hadgu et al., 1995), grid generation programs, and a number of utility routines for pre- and post-processing of data.

\begin{tabular}{|c|c|}
\hline MODULE(status) & PURPOSE \\
\hline $\mathrm{T} 2 \mathrm{CG} 1(\mathrm{PR})$ & $\begin{array}{l}\text { preconditioned conjugate gradient solvers for simulation of large } 2-D \text { and } \\
3-D \text { problems with } 10,000 \text { grid blocks or more }\end{array}$ \\
\hline TOUGH 2 for $P C(P R)$ & adaptation of TOUGH2 for Personal Computers (PC) \\
\hline T2VOC $(\mathrm{PR})$ & $\begin{array}{l}\text { a module for 3-phase, 3-component flow of water, air, and a volatile organic } \\
\text { compound (VOC) }\end{array}$ \\
\hline ITOUGH2 $(\beta)$ & $\begin{array}{l}\text { inverse modeling, allowing automatic model calibration (history matching), } \\
\text { and process optimization, with applications to test design, reservoir } \\
\text { management, and environmental remediation }\end{array}$ \\
\hline $\mathrm{T} 2 \mathrm{DM}(\beta)$ & strongly coupled flow and transport, with full hydrodynamic dispersion \\
\hline $\operatorname{EOS6}(\mathbf{i})$ & fluid property module for water with silica dissolution and precipitation \\
\hline $\operatorname{EOS7}(\beta)$ & fluid property module for mixtures of water, brine, and air \\
\hline $\operatorname{EOS7R}(\beta)$ & $\begin{array}{l}\text { fluid property module for water, brine, air, plus volatile tracers with optional } \\
\text { parent - daughter chain decay }\end{array}$ \\
\hline $\operatorname{EOS} 8(\beta)$ & $\begin{array}{l}\text { fluid property module for three-phase flow of water, non-condensible gas, } \\
\text { and black oil }\end{array}$ \\
\hline $\operatorname{EOS} 9(\beta)$ & $\begin{array}{l}\text { fluid property module for saturated/unsaturated flow according to Richards' } \\
\text { equation (gas phase a passive bystander) }\end{array}$ \\
\hline EWASG $(\mathbf{i})$ & $\begin{array}{l}\text { fluid property module for three-component two-phase mixtures of water, } \\
\text { water-soluble salt, and non-condensible gas; includes salt dissolution and } \\
\text { precipitation, and associated porosity and permeability change }\end{array}$ \\
\hline $\mathrm{ECH} 4(\mathbf{i})$ & fluid property module for water and methane \\
\hline $\operatorname{EGEL}(\beta)$ & $\begin{array}{l}\text { fluid property module for two-phase flow of an aqueous and a gas phase, } \\
\text { where the aqueous phase may consist of a mixture of water and a gelling } \\
\text { fluid }\end{array}$ \\
\hline $\operatorname{EOSNN}(\beta)$ & $\begin{array}{l}\text { fluid property module for three-phase flow of water, non-condensible gas, } \\
\text { and a non-Newtonian fluid }\end{array}$ \\
\hline $\operatorname{EOS} 1 G(\beta)$ & fluid property module for single-phase gas flow \\
\hline MULH(i) & $\begin{array}{l}\text { flow in strongly heterogeneous media (spatially correlated random } \\
\text { permeability fields) }\end{array}$ \\
\hline T2HYST $^{(\mathbf{i})}$ & hysteretic capillary pressure relationships \\
\hline
\end{tabular}


1995) presented detailed analysis of 16 fluid and heat . flow problems, with as many as 20,000 coupled equations on different computer platforms (workstations, PCs, Macintosh).

TOUGH2 requires 64-bit arithmetic, while current workstations, PCs, and Macintoshes have 32-bit processors. FORTRAN compilers on workstations usually provide a "double precision" option which can generate a double-precision executable at compile time from single-precision code. Because such options have not been generally available on PCs and Macintoshes, we have created a version of TOUGH2 which is intrinsically double-precision. "TOUGH2 for PC" comes with a number of utility files and programs to facilitate implementation on these inexpensive and widely available machines (Antúnez et al., 1995). Flow problems with up to 800 grid blocks, 2,400 connections, and 3 equations per grid block can be solved with 4 Megabytes of RAM. Memory requirements for larger problems can be estimated by noting that the size of the largest arrays in TOUGH2 is proportional to

$$
M=(N E L+2 * N C O N) * N E Q * N E Q
$$

where NEL is the number of grid blocks (elements), NCON is the number of connections between them, and NEQ is the number of equations (mass and heat balances) per grid block. Accordingly, simulation of a problem with 8,000 grid blocks, 24,000 connections, and 2 equations per grid block would require approximately $18 \mathrm{MB}$ of RAM.

T2VOC is a module recently released through ESTSC, which was primarily designed for environmental contamination problems involving volatile organic chemicals (VOCs; Falta et al., 1995). However, T2VOC retains the full two-phase coupled fluid and heat flow capabilities of geothermal modules of TOUGH2, so that it is applicable to the migration of volatile tracers in two-phase geothermal reservoirs.

\section{INVERSE MODELING}

An important new development is the ITOUGH2 code for "inverse" modeling
(Finsterle, 1993; Finsterle and Pruess, 1995a, b; Finsterle et al., 1996). ITOUGH2 repeatedly calls the "normal" TOUGH2 code in an iterative process, automatically adjusting model parämeters (such as reservoir permeability and porosity) to improve and optimize agreement between simulated results and field data. This overcomes the time- and labor-intensive tedium of traditional history matching (model calibration) through trialand-error parameter adjustment "by hand." It also provides objective measures of "goodness of fit," such as error analysis and parameter sensitivities.

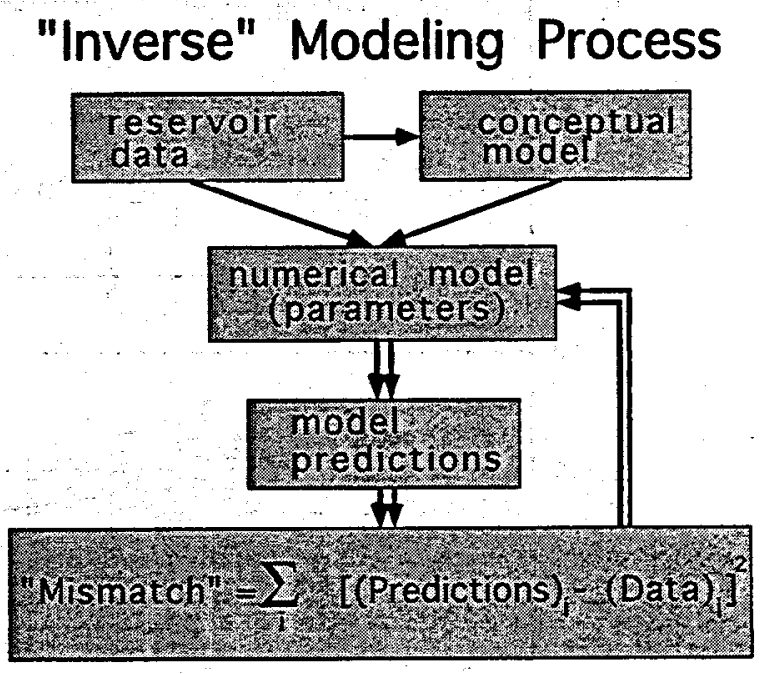

Figure 1. Schematic of the inverse modeling approach. The process of automatically readjusting model parameters (shown by double arrows) continues until model calibration (history match) is optimized.

The inverse modeling process is illustrated in Figure 1. "Hard" and "soft" data are used to first construct a conceptual model of the reservoir. This forms the basis for a numerical model which typically involves a number of unknown or poorly known parameters (e.g., permeability and porosity distributions, reservoir size and boundary conditions, etc.). Conventional "forward" reservoir simulation is then used to generate reservoir performance predictions. These predictions are compared with field data and, based on the observed mismatch, the parameters of the numerical model are automatically revised in a manner that will reduce the mismatch. The.process of automated parameter revisions is continued, in 
an iterative way, until model calibration (history match) is optimized.

Figure 2 shows an example of an automatic history match that was obtained for a set of synthetic reservoir performance data which were generated with a TOUGH2 run. The reservoir is a five-spot production-injection system previously studied by Pruess and Wu
(1993). Thermodynamic conditions are typical for deep zones of two-phase reservoirs. Random noise was added to the forward simulation data to simulate measurement errors. Automatic model calibration is seen to produce excellent agreement with the synthetic data. Model parameters were found to agree well with the specifications used in the forward runs.
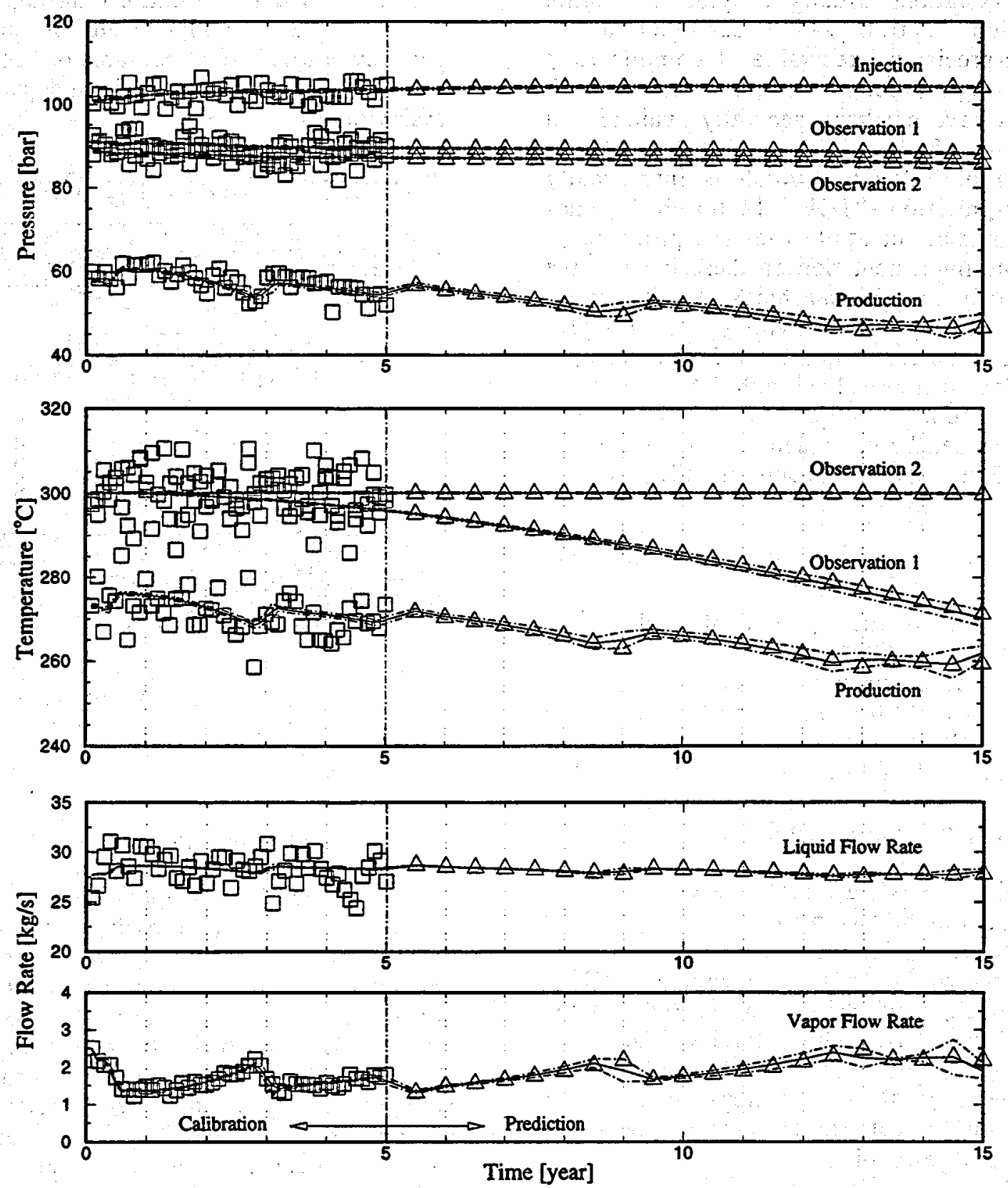

Figure 2. Calibration and prediction of pressures, temperatures, water and vapor flow rates. Squares are synthetic data points used for calibration. Triangles represent the true system response. Simulation results based on the estimated parameter set are shown as solid lines. Error bands (dash-dotted lines) are calculated using linear error propagation analysis (from Finsterle and Pruess, 1995). 


\section{ENHANCED PROCESS DESCRIPTION}

Several new fluid property modules provide capabilities for handling saline fluids (Oldenburg et al., 1995; Battistelli et al 1995a, b). EOS7 describes variable-salinity fluids as mixtures of water and $\mathrm{NaCl}$ brine, while EOS7R includes an additional capability for tracers with parent-daughter chain decay. These tracers can partition between aqueous and gas phases, and sorb on reservoir rocks.

While the description of saline fluids as waterbrine mixtures is computationally very efficient, it is not applicable under conditions where solubility constraints may come into play, e.g., due to extensive boiling of a saline reservoir. This may give rise to precipitation and dissolution of salt which can be modeled with the EWASG module. EWASG keeps track of porosity and permeability changes when $\mathrm{NaCl}$ precipitates or dissolves. It also models vapor pressure-lowering effects from both fluid salinity and suction pressures (capillary and vapor adsorption effects). Several choices are available for the non-condensible gas $\left(\mathrm{CO}_{2}\right.$, air, $\left.\mathrm{CH}_{4}, \mathrm{H}_{2}, \mathrm{~N}_{2}\right)$, and changes in gas solubility with salinity are included ("salting out").

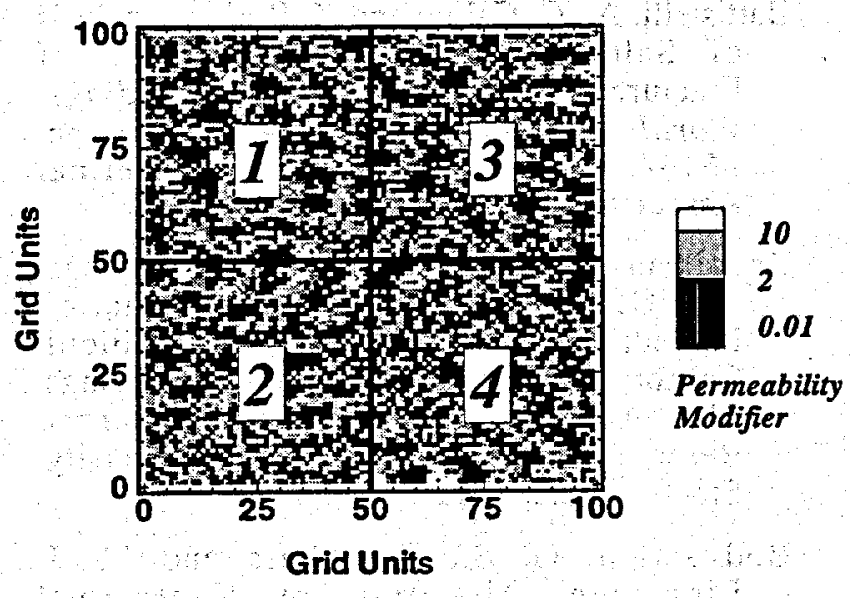

Figure 3. A spatially-correlated random field for representing heterogeneous fractures. Permeability modifiers in the four quadrants labeled $1-4$ are used separately in numerical simulation experiments (from Pruess, 1996b).
A capability for modeling mass transport by molecular diffusion and hydrodynamic dispersion has been developed (T2DM). At the present time, this is limited to two-dimensional reservoir domains with a rectangular grid structure. The strong coupling between mass transport and fluid flow, primarily due to the dependence of fluid density on salinity, was found to give rise to complex flow behavior (Oldenburg and Pruess, 1995). Dispersive behavior can also arise in the process of immiscible displacement of reservoir steam by injected water in heterogeneous fractures (Pruess, 1996a).

Another active area of simulator development and application relates to the multi-scale heterogeneities found in fractured reservoirs. Geostatistical methods are being used to generate spatially-correlated random fields which can represent aperture distributions in natural rough-walled rock fractures (module MULH; Pruess and Antunez, 1995). As an example, Figure 3 shows computer-generated permeability fields that were used to investigate fundamental issues relating to water injection into fractured vapor-dominated reservoirs such as The Geysers. An example of a simulated injection plume is shown in Figure 4 (Pruess, 1996b).

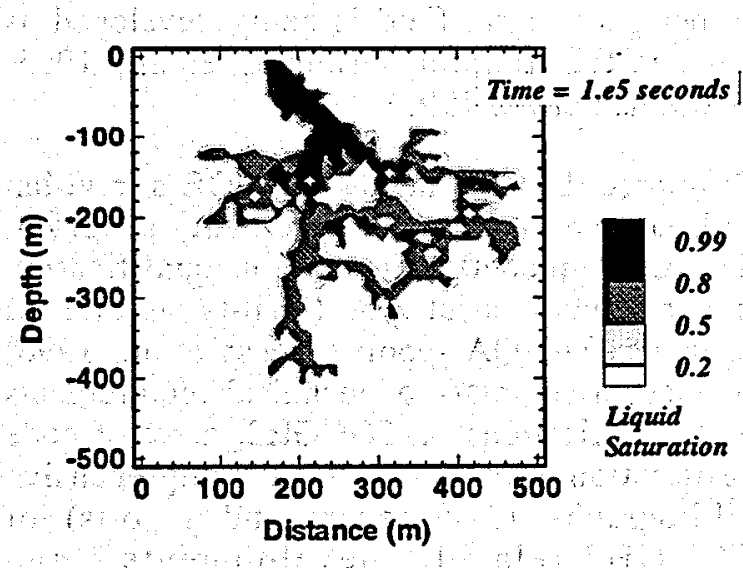

Figure 4. Simulated plume for injection at a rate of $10 \mathrm{~kg} / \mathrm{s}$ over $10^{5}$ seconds into a heterogeneous fractures, corresponding to the quadrant \# 3 of the permeability field shown in Fig. 3 (from Pruess, 1996b). 


\section{TECHNOLOGY TRANSFER}

The LBNL group serves as custodians of the TOUGH/MULKOM codes, and provides limited technical support to the user community which presently numbers approximately 150 organizations in 22 countries. Our general aim is to foster an open, interactive environment that can attract and induce other researchers to use, improve, and share codes for mutual benefit. We also encourage development of user support services and code enhancements in the private sector.

The TOUGH Workshop '95, held in March 1995 at LBNL, was attended by approximately 100 participants from 10 countries. The proceedings feature 53 technical papers in different areas, including geothermal reservoir engineering, oil : and gas, nuclear waste isolation, environmental remediation, mining engineering, vadose zone hydrology, and simulation methods (Pruess, 1995).

Under a DOE-LBNL agreement with the California Department of Conservation, Division of Oil, Gas, and Geothermal Resources (DOGGR), DOGGR engineers are currently being trained in the use of TOUGH2-PC. The objective is to help DOGGR enhance their supervisory role of geothermal fields. A numerical model of the Heber geothermal field is being developed as part of this training (Antúnez et al., 1995; Boardman et al., 1996).

Prompted by the needs of DOE's civilian radioactive waste management program, TOUGH2 recently underwent qualification under a very strict QA (quality assurance) program. The QA report (Pruess et al., 1996) includes a summary of technical requirements and specifications of TOUGH2, a set of code verification problems, and a comprehensive bibliography (318 papers and reports) of TOUGH2-related developments and applications.

\section{ACKNOWLEDGEMENT}

The authors are indebted to Drs. M. Lippmann and G.S. Bodvarsson for their critical review of the manuscript and the suggestion of improvements. We wish to acknowledge many valuable contributions from our collaborators outside LBNL: A. Battistelli, D. Bullivant, C. Calore, R. Falta, and M.J. O'Sullivan. This work was supported by the Assistant Secretary for Energy Efficiency and Renewable Energy, Geothermal Division, U.S. Department of Energy under Contract No. DE-AC0376 SF00098.

\section{REFERENCES}

Antúnez, E., M. Lippmann, M. Ali-Khan, and T. Boardman. Simulation of the Heber Geothermal Field, a TOUGH2/PC Application, Proceedings of the TOUGH Workshop '95, Lawrence Berkeley Laboratory Report LBL-37200, pp. 101 106, Berkeley, CA, March 1995.

Antúnez, A., G. Moridis and K. Pruess. LargeScale Three-Dimensional Geothermal Reservoir Simulation on Small Computer Systems. Proceedings, World Geothermal Congress 1995, pp. 2977-2980, International Geothermal Association, May 1995.

Battistelli, A., C. Calore and K. Pruess. Vapor Pressure Lowering Effects due to Salinity and Suction Pressure in the Depletion of Vapor-Dominated Geothermal Reservoirs, Proceedings, TOUGH Workshop '95, pp. 77-83, Berkeley, CA, March 1995a.

Battistelli, A., C. Calore and K. Pruess. Analysis of Salt Effects on the Depletion of Fractured Reservoir Blocks. Proceedings, World Geothermal Congress 1995, pp. 1613-1618, International Geothermal Association, May $1995 \mathrm{~b}$.

Boardman, T., M. Ali-Khan and E. Antúnez. TOUGH2-PC Application Simulation Project for Heber Geothermal Field, California. A Progress Report. Proceedings, 21st Annual Workshop on Geothermal Reservoir Engineering, Stanford University, Stanford, CA, January 1996.

Bodvarsson, G. S., K. Pruess and M. J. Lippmann. Modeling of Geothermal Systems, J. Pet. Tech., 38 (10), 1007-1021, September 1986.

Falta, R.W., K. Pruess, S. Finsterle, and A. Battistelli. T2VOC User's Guide, Lawrence Berkeley Laboratory Report LBL-36400, March 1995. 
Finsterle, S. ITOUGH2 User's Guide, Version 2.2. Lawrence Berkeley Laboratory Report LBL-34581, December 1993.

Finsterle, S. and K. Pruess. Solving the Estimation-Identification Problem in TwoPhase Flow Modeling. Water Resources Res., Vol. 31, No. 4, pp. 913-924, April 1995 .

Finsterle, S. and K. Pruess. Automatic History Matching of Geothermal Field Performance. Proceedings, 17th New Zealand Geothermal Workshop, Auckland, New Zealand, pp. 193-198, November 1995b (also: Lawrence Berkeley National Laboratory Report LBL-37611).

Finsterle, S., D. Bullivant and M.J. O'Sullivan. Automatic History Matching of Geothermal Performance Data. To be presented at SPE Annual Fall Technical Conference and Exhibition, 1996.

Hadgu, T., R.W. Zimmerman and G.S. Bodvarsson. Coupled Reservoir-Wellbore Simulation of Geothermal Reservoir Behavior. Geothermics, Vol. 24, No. 2, pp. 145-166, 1995.

Moridis, G. and K. Pruess. Flow and Transport Simulations Using T2CG1, a Package of Conjugate Gradient Solvers for the TOUGH2 Family of Codes. Lawrence Berkeley Laboratory Report LBL-36235, April 1995.

Oldenburg, C.M., K. Pruess and M. Lippmann. Heat and Mass Transfer in Hypersaline Geothermal Systems. Proceedings, World Geothermal Congress 1995, pp. 16471652, International Geothermal Association, May 1995.

Oldenburg, C.M. and K. Pruess. Dispersive Transport Dynamics in a Strongly Coupled Groundwater-Brine Flow System. Water Resour. Res., Vol. 31, No. 2, pp. 289-302, February 1995.

Pruess, K. TOUGH2 - A General Purpose Numerical Simulator for Multiphase Fluid and Heat Flow, Report No. LBL-29400, Lawrence Berkeley Laboratory, Berkeley, CA, May 1991 .

Pruess, K. (editor). Proceedings of the TOUGH Workshop ' 95 , Lawrence Berkeley Laboratory Report LBL-37200, March 1995.
Pruess, K. A Fickian Diffusion Model for the Spreading of Liquid Plumes Infiltrating in Heterogeneous Media. To appear in Transport in Porous Media, 1996a.

Pruess, $\mathrm{K}$. Injection Plume Behavior in Fractured, Vapor-Dominated Reservoirs. Lawrence Berkeley Laboratory Report LBL-38089, presented at 21st Annual Workshop on Geothermal Reservoir Engineering, Stanford University, Stanford, CA, January 1996b.

Pruess, K. and Y.S. Wu. A New Semianalytical Method for Numerical Simulation of Fluid and Heat Flow in Fractured Reservoirs, SPE Advanced Technology Series, Vol. 1, No. 2, pp. 63-72, 1993.

Pruess, K. and E. Antunez. Applications of TOUGH2 to Infiltration of Liquids in Media with Strong Heterogeneity, Proceedings of the TOUGH Workshop '95, Lawrence Berkeley Laboratory Report LBL-37200, pp. 69-76), Berkeley, CA, March 1995.

Pruess, K., A. Simmons, Y.S. Wu and G. Moridis. TOUGH2 Software Qualification. Lawrence Berkeley National Laboratory Report LBL-38383, February 1996. 